\title{
CAPÍTULO 53: DO RIO À MESA, O CONSUMO DE PESCADOS NA AMAZÔNIA: PERFIL DO CONSUMIDOR E CRITÉRIOS DE COMPRA EM BELÉM (PA)
}

\section{CHAPTER 53: FROM RIO TO TABLE, FISH CONSUMPTION IN THE AMAZON: CONSUMER PROFILE AND PURCHASE CRITERIA IN BELÉM (PA)}

\author{
Flavio Henrique Sousa Lobato $^{1}$; Matheus Yuri de Oliveira Rosa ${ }^{2}$
}

\begin{abstract}
Resumo
Diversas iniciativas têm promovido campanhas buscando aumentar o consumo de pescados no Brasil, dado os benefícios dos componentes nutricionais desse tipo alimento. Contudo, é imprescindível que, no momento da compra, vários aspectos sejam levados em consideração para garantir que os peixes estejam em condições apropriadas para o consumo. Diante disso, este trabalho teve como objetivo identificar o perfil e os critérios de compra e consumo de peixes por consumidores que frequentavam o Mercado Municipal do Distrito de Icoaraci, Belém (PA), a fim de investigar não apenas a regularidade de consumo, mas também os parâmetros de qualidade adotados no momento da aquisição dos pescados. Para tanto, foram realizadas pesquisas bibliográficas, documentais e de campo. A coleta de dados foi estabelecida a partir da aplicação de um questionário, com 25 perguntas semiestruturadas acerca de aspectos socioeconômicos e critérios como cor, sabor e textura dos pescados, bem como sobre a frequência e as formas de consumo, junto a 120 consumidores. Os resultados revelaram que até existe uma preocupação em adquirir e consumir alimentos com boa qualidade, mas a condição financeira, as formas de oferta e o baixo custo dos produtos inviabilizam a adoção de tais cuidados.
\end{abstract}

Palavras-Chave: Pescado, Perfil, Compra, Consumo, Mercado de Icoaraci.

\begin{abstract}
Several initiatives have promoted campaigns aimed at increasing fish consumption in Brazil, given the benefits of the nutritional components of this type of food. However, it is essential that, at the time of purchase, several aspects are taken into account to ensure that the fish are in conditions suitable for consumption. Therefore, this work aimed to identify the profile and the criteria for the purchase and consumption of fish by consumers who attended the Municipal Market in the District of Icoaraci, Belém (PA), to investigate not only the regularity of consumption, but also the quality parameters adopted in the purchase of the fish. To this end, bibliographic, documentary and field research were carried out. The data collection was established from the application of a questionnaire, with 25 semi-structured questions about socio-economic aspects and criteria such as color, flavor and texture of fish, as well as the frequency and forms of consumption, with 120 consumers. The results revealed that there is a concern to acquire and consume good quality food, but the financial condition, the forms of supply and the low cost of the products make the adoption of such care unfeasible.
\end{abstract}

Keywords: Fish, Profile, Purchase, Consumption, Icoaraci Market.

\footnotetext{
${ }^{1}$ Programa de Pós-Graduação em Desenvolvimento Sustentável do Trópico Úmido, Universidade Federal do Pará (NAEA/UFPA), flaviohslobato@ @mail.com;

${ }^{2}$ Acadêmico de Tecnologia de Alimentos. Universidade do Estado do Pará (UEPA), matheusyurid@ gmail.com.
} 


\section{Introdução}

Os pescados têm grande destaque nutricional em comparação aos demais alimentos de origem animal, pois possuem acentuadas quantidades de vitaminas lipossolúveis A e D, cálcio, fósforo, ferro, cobre, selênio e, no caso dos peixes de água salgada, iodo. Ademais, os peixes contêm alta proporção de ácidos graxos poli-insaturados de cadeia longa com cinco ou seis ligações duplas, o que beneficia tanto na saúde quanto na atividade antitrombótica humana (MATEUS et al., 2019; SOUSA; ALMEIDA, 2018). Destarte, auxilia na redução dos triacilgliceróis séricos e de alergias crônicas e atua na prevenção de aterosclerose e trombose (SILVA et al., 2017).

No mais, outros estudos (DURAN, et al., 2016; MACIEL et al., 2019; MATEUS et al., 2019; PINHEIRO et al., 2020) elencam como benefícios de um consumo regular de pescados: a minimização do risco de Acidente Vascular Cerebral (AVC), o combate à depressão e ao mal de Alzheimer, a redução de mortes por doenças cardíacas e a prevenção de certos tipos de câncer. Desse modo, nota-se que os peixes e seus derivados são importantes para melhoria da qualidade da alimentação, especialmente das crianças, tendo em vista que o ácido graxo ômega3, de acordo com diversos estudos (BARROS et al., 2019; CALDER, 2017; DURAN, et al., 2016; SUÁREZ et al. 2018), compreende um elemento basilar para otimizar o sistema nervoso de crianças e adolescentes, auxiliando no aprendizado e na coordenação mental, emergindo resultados positivos no que diz respeito ao crescimento corporal e ao intelecto na criança (LUZ et al., 2020; SILVA et al., 2017; SUÁREZ et al. 2018).

A Organização das Nações Unidas para Alimentação e Agricultura (FAO, 2016) recomenda a ingestão de pescados e derivados por pelo menos duas vezes por semana, em face de sua alta capacidade de manter, promover e/ou resgatar a saúde dos que consomem. O Brasil obteve média de consumo anual per capita de pescado em torno de $10 \mathrm{~kg} /$ per capita, em 2018, dado considerado baixo em relação à quantidade, recomendada pela FAO, para o consumo de 12 kg/per capita (MEDEIROS, 2019). Na particularidade amazônica, entretanto, não há grande preocupação com a ingestão contínua de pescados, tendo em vista que o Estado do Pará - por possuir uma abundância de peixes e uma forte valorização cultural desse alimento herdada dos povos indígenas - é um dos estados que mais consome pescados no Brasil, sendo um gênero alimentício marcante no cotidiano local (LOPES et al., 2020; LOPES; OLIVEIRA; RAMOS, 2016). Na pesquisa desenvolvida por Lopes, Oliveira e Ramos (2016), a Região Norte aparece em primeiro lugar no consumo de pescados no país, com $70 \%$ da amostra investigada. Por outro lado, a Região Sudeste - que concentra o maior quantitativo populacional - ocupou o último lugar, com somente $15,2 \%$. 
No contexto amazônico, as feiras livres e os mercados populares compreendem os espaços principais de comercialização de pescados e outros mais gêneros alimentícios, tendo uma acentuada importância econômica e cultural na região (LOBATO; RAVENA-CAÑETE, 2019). No entanto, esses espaços têm sido indicados por diversos estudos como propícios à contaminação de alimentos em face de suas precárias condições higiênico-sanitárias (FERREIRA, 2019; LOPES et al., 2020; ROSA et al., 2019; SANTOS et al., 2019). Dessa forma, “[...] os benefícios nutricionais dos pescados somente podem ser aproveitados quando os fatores segurança e qualidade forem garantidos [...]" (ROSA et al., 2019, p. 2). Afinal, não basta ter um consumo regular de pescados se estes não estiverem em boa qualidade e, por conseguinte, apropriados para o consumo.

O presente trabalho objetivou identificar o perfil e os critérios de compra e de consumo de pescados por consumidores que frequentavam o Mercado Municipal do Distrito de Icoaraci, Belém (PA), a fim de não somente compreender se eles têm consumido ou não esse alimento de maneira assídua, mas identificar quais os parâmetros ou os critérios mínimos de qualidade são adotados na hora de escolher os peixes e os locais de comercialização.

\section{Material e Métodos}

O estudo, com uma abordagem qualitativa e quantitativa, utilizou como técnicas de pesquisa levantamentos bibliográficos e documentais em bases e plataformas de conteúdo científico (PRODANOV; FREITAS, 2013). A pesquisa de campo ocorreu entre os dias 13 de novembro e 17 de dezembro de 2019, a partir de um questionário aplicado junto a 120 consumidores que à época frequentaram o Mercado Municipal do Distrito de Icoaraci, Belém (PA), e aceitaram participar da pesquisa, sendo uma amostra, portanto, por conveniência. Tal instrumento de coleta de dados foi composto por 25 perguntas semiestruturadas relacionadas aos aspectos socioeconômicos, às formas e aos critérios de aquisição, de consumo e de preparo de pescados. Convém pontuar que todos os sujeitos foram convidados a participar da pesquisa de forma espontânea e voluntária, por meio da assinatura do Termo de Consentimento Livre e Esclarecido (TCLE), a qual foi antecedida de uma conversa para explicar sobre a utilização dos dados e do TCLE, bem como a relevância da pesquisa.

Os dados obtidos foram tabulados e sistematizados em tabelas no Microsoft Office Excel 2013 e analisados pela técnica da Estatística Descritiva em diálogo com dados secundários obtidos em pesquisas documentais (BRASIL, 1997, 2012, 2016; FAO, 2016) e com as discussões teóricas acessadas pelas pesquisas bibliográficas (LEANDRO et al., 2018; LOPES; OLIVEIRA; RAMOS, 2016; ROSA et al., 2019; SANTOS et al., 2017; SILVA et al., 2017), a 
fim de identificar um perfil de compra e consumo de pescado entre os consumidores que constituíram a amostra do estudo.

\section{Resultados e Discussão}

A partir da aplicação dos questionários, constatou-se que dos 120 consumidores participantes da pesquisa, $70 \%(n=84)$ eram do sexo feminino e $30 \%(n=36)$ do sexo masculino. Com relação à faixa-etária, 13,33\% $(\mathrm{n}=16)$ dos participantes tinham entre 18 e 25 anos, 20\% ( $\mathrm{n}=24)$ de 26 a 35 anos, $35 \%(\mathrm{n}=42)$ tinham entre 36 e 45 anos, $28,33 \%(\mathrm{n}=34)$ de 46 a 55 anos e, por fim, 3,33\% ( $(n=4)$ tinham mais de 55 anos. Entre os consumidores, 7,5\% $(\mathrm{n}=9)$ moravam sozinhos(as), 27,5\% $(\mathrm{n}=33)$ moravam com 1 ou 2 pessoas, 40,83\% $(\mathrm{n}=49)$ com 3 ou 4 pessoas e 24,17\% $(n=29)$ residiam com 5 ou mais pessoas. No mais, acerca da renda familiar mensal, os resultados obtidos indicaram que 32,5\% $(\mathrm{n}=39)$ tinham renda per capita menor que 1 salário mínimo, 47,5\% ( $\mathrm{n}=57)$ entre 1 e 3 salários mínimos e 20\% (n=24) entre 4 e 6 salários mínimos, conforme dispõe os dados da Tabela 1. Tais dados são indicativos importantes do perfil socioeconômico do consumidor de pescados do Mercado Municipal de Icoaraci, tendo em vista que alguns percentuais como o das mulheres, o número de pessoas por residência e a renda mensal são marcadores da compra e do volume de consumo dos peixes.

Em estudo semelhante, Alho (2019, p. 35) - ao analisar o contexto de consumo de peixe no Mercado de Ferro do Ver-o-Peso, em Belém - revela que “[...] os fatores que influenciam o comportamento do consumidor, não estão relacionados somente a fatores intrínsecos ao peixe, mas também a fatores que correspondem ao perfil socioeconômico do consumidor". Alho (2019, p. 35) reitera ainda que as características socioeconômicas "[...] podem ser fatores limitantes e/ou facilitadores do consumo de peixe, tendo em vista que: as mulheres são quem normalmente fazem a compra do pescado; a idade pode influenciar, pois os mais velhos são normalmente quem conhecem as espécies de peixe". No entanto, além dos aspectos socioeconômicos, é importante ressaltar que a abundância de recursos e a influência cultural indígena possuem grande influência no consumo de peixes no Distrito de Icoaraci, tendo em vista que o mercado é um dos espaços principais para o abastecimento de famílias de baixa renda (ROSA et al., 2019), assim como ocorre no município de Sinop (MT), segundo Leandro et al. (2018). 
Tabela 1. Perfil sinótico de 120 consumidores do Mercado Municipal do Distrito de Icoaraci que participaram da pesquisa que subsidiou este trabalho

\begin{tabular}{|c|c|c|c|}
\hline \multicolumn{2}{|c|}{ Dados socioeconômicos } & \multirow{2}{*}{$\begin{array}{l}n \\
84\end{array}$} & \multirow{2}{*}{$\begin{array}{c}\% \% \\
70 \%\end{array}$} \\
\hline Sovo & Feminino & & \\
\hline sexo: & Masculino & 36 & $30 \%$ \\
\hline \multirow{5}{*}{ Faixa-etária: } & De 18 a 25 anos & 16 & $13,33 \%$ \\
\hline & De 26 a 35 anos & 24 & $20 \%$ \\
\hline & De 36 a 45 anos & 42 & $35 \%$ \\
\hline & De 46 a 55 anos & 34 & $28,33 \%$ \\
\hline & Mais de 55 anos & 4 & $3,33 \%$ \\
\hline \multirow{4}{*}{ Estado civil: } & Solteiro(a) & 41 & $34,17 \%$ \\
\hline & Casado(a) & 46 & $38,33 \%$ \\
\hline & Divorciado(a) & 23 & 19,17 \\
\hline & Viúvo(a) & 11 & 9,17 \\
\hline \multirow{4}{*}{ Renda per capita } & Menor que 1 salário mínimo & 39 & $32,5 \%$ \\
\hline & De 1 a 3 salários mínimos & 57 & $47,5 \%$ \\
\hline & De 4 a 6 salários mínimos & 24 & $20 \%$ \\
\hline & Mais de 6 salários mínimos & 0 & $0 \%$ \\
\hline \multirow{4}{*}{$\begin{array}{l}\text { Quantidade de moradores } \\
\text { na residência dos } \\
\text { consumidores: }\end{array}$} & Mora sozinho(a) & 9 & $7,5 \%$ \\
\hline & De 1 a 2 pessoas & 33 & $27,5 \%$ \\
\hline & De 3 a 4 pessoas & 49 & $40,83 \%$ \\
\hline & 5 ou mais pessoas & 29 & $24,17 \%$ \\
\hline
\end{tabular}

Fonte: Própria (2019).

Na busca por identificar o perfil de compra e consumo de pescados dos consumidores, por meio do instrumento de coleta de dados (questionário), perguntou-se qual o tipo de pescado mais consumido entre eles. Após a tabulação (Tabela 2), os resultados obtidos revelaram que $70 \%(\mathrm{n}=84)$ assinalaram que o peixe era, na época da pesquisa, o tipo de pescado mais consumido, seguido de $21,6 \%$ o camarão $(n=26), 4,15 \%$ as ostras $(n=5), 3,33 \%$ o caranguejo $(n=4)$ e $0,83 \%$ o mexilhão $(n=1)$. As espécies de peixe mais consumidas eram: Tambaqui com 44,16\%, seguido do Tucunaré (40,83\%), Mapará (1,6\%), Dourada (1,6\%), Tilápia $(0,83 \%)$, Curimatã $(0,83 \%)$ e outras espécies não identificadas, que somadas corresponderam $10 \%$.

O elevado percentual de consumo de peixe pelos consumidores entrevistados deve-se à disponibilidade acentuada de peixe na região, fato que influencia a comercialização e o consumo - dada a facilidade de encontrar esse alimento a custos mais baixos. Nesse sentido, cumpre destacar que, segundo o Anuário Peixe BR da Psicultura 2019, a Região Norte ocupa a segunda colocação da produção de pescados do Brasil (153.020 toneladas), sendo o Estado do Pará responsável por 23.720 toneladas, mostrando ser o líder das Regiões Norte e Nordeste na 
produção de Tilápia (MEDEIROS, 2019).

Tabela 2. Pescado mais consumido entre os 120 consumidores do Mercado Municipal do Distrito de Icoaraci participantes da pesquisa que subsidiou este trabalho

\begin{tabular}{lcc}
\hline \multicolumn{1}{c}{ Qual pescado de maior consumido } & $\mathbf{n}$ & $\mathbf{\%}$ \\
\hline Peixes & 84 & $70,00 \%$ \\
Ostras & 5 & $4,15 \%$ \\
Caranguejo & 4 & $3,33 \%$ \\
Camarão & 26 & $21,6 \%$ \\
Mexilhão & 1 & $0,83 \%$ \\
\hline Total & $\mathbf{1 2 0}$ & $\mathbf{1 0 0 \%}$ \\
\hline
\end{tabular}

Fonte: Própria (2019).

No tocante à forma de compra do pescado, 53,33\% $(\mathrm{n}=64)$ do total de consumidores $(\mathrm{n}=120)$ disse que compra normalmente congelado, 23,33\% $(\mathrm{n}=28)$ vivo, 21,67\% $(\mathrm{n}=26)$ resfriado, $20 \%(\mathrm{n}=24)$ in natura e 17,5\% $(\mathrm{n}=21)$ salgado (Tabela 3). Levando em consideração o contexto do Distrito de Icoaraci, a maior parte optava por adquirir o produto na forma congelado por ele ter frequentemente valores mais baixos e ser mais acessível que as demais formas. No caso específico dos pescados salgados, por normalmente terem passado por um processo de beneficiamento (salgamento e secagem), logo demandarem maior trabalho, são os com maiores valores. No mais, os vivos e os in natura são menos consumidos pela pouca disponibilidade nos locais de venda e por serem em geral mais caros, uma vez que possuem maior frescor.

Tabela 3. Forma de compra do pescado entre os 120 consumidores do Mercado Municipal do Distrito de Icoaraci participantes da pesquisa que subsidiou este trabalho

\begin{tabular}{lccc}
\hline Forma de compra do pescado & Sim & Não & Total \\
\hline Congelado & $53,33 \%$ & $46,67 \%$ & $100,0 \%$ \\
Resfriado & $21,67 \%$ & $78,33 \%$ & $100,0 \%$ \\
Vivo & $23,33 \%$ & $76,67 \%$ & $100,0 \%$ \\
In natura & $20 \%$ & $80 \%$ & $100,0 \%$ \\
Salgado & $17,5 \%$ & $82,5 \%$ & $100,0 \%$ \\
\hline
\end{tabular}

Fonte: Própria (2019).

Em face de o pescado ser um produto bastante perecível, deve-se atentar para os locais 
onde são comercializados e os fatores relevantes na hora da compra. Segundo os dados da Tabela 4, 40\% dos participantes da pesquisa optavam por comprar em peixarias, $34 \%$ em supermercado, 19\% em feiras livres e 7\% em outros locais. Em diálogo com estas informações, os dados da Tabela 5 mostram quais são os fatores relevantes na hora da compra do pescado, ao informar que: $68 \%$ dos consumidores indicaram que suas famílias buscam por um produto de qualidade, $9 \%$ optam por um bom atendimento, o preço $8 \%$, comodidade $0 \%$ e outros fatores 5\%. Em estudo semelhante realizado no Mercado de Ferro do Ver-o-Peso, em Belém (PA), notou-se que há uma diferenciação entre mulheres e homens quanto aos fatores de compra, enquanto as mulheres “[...] são as que mais se preocupam com a melhor qualidade dos pescados, demonstrando que o motivo mais relevante na hora da compra seria a "Higiene" $(23,00 \%)$. Os homens, por outro lado, afirmaram optar pelo "Menor preço" (12,00\%)" (ALHO, 2019, p. 29).

Tabela 4. Local que geralmente é realizada a compra dos pescados entre os 120 consumidores do Mercado Municipal do Distrito de Icoaraci participantes da pesquisa que subsidiou este trabalho

\begin{tabular}{lcc}
\hline Local de compra do pescado & n & \% \\
\hline Feira livre & 23 & $19,16 \%$ \\
Supermercado & 41 & $34,16 \%$ \\
Peixaria & 48 & $40 \%$ \\
Outros & 8 & $6,67 \%$ \\
\hline Total & $\mathbf{1 2 0}$ & $\mathbf{1 0 0 \%}$ \\
\hline
\end{tabular}

Fonte: Própria (2019).

Tabela 5. Fator relevante na hora da compra do pescado entre os 120 consumidores do Mercado Municipal do Distrito de Icoaraci participantes da pesquisa que subsidiou este trabalho

\begin{tabular}{lrr}
\hline Fator relevante na hora da compra & n & \% \\
\hline Atendimento & 15 & $12.5 \%$ \\
Qualidade & 81 & $67,5 \%$ \\
Comodidade & 0 & $0 \%$ \\
Preço & 14 & $11,66 \%$ \\
Outros & 10 & $8,33 \%$ \\
\hline Total & $\mathbf{1 2 0}$ & $\mathbf{1 0 0 , 0}$ \\
\hline
\end{tabular}

Fonte: Própria (2019).

Estas informações indicam uma preferência por peixarias, em razão da variedade das espécies comercializadas, e por supermercados em virtude da ideia preconcebida de que são 
espaços que apresentam melhores condições higiênico-sanitárias, dado que vai ao encontro do percentual de consumidores que têm como fator mais importante no momento da compra a qualidade dos pescados. Em estudo semelhante realizado no Mercado de Ferro do Ver-o-Peso, em Belém (PA), por Alho (2019), notou-se ainda uma diferenciação entre os gêneros durante a compra. Enquanto as mulheres "[...] são as que mais se preocupam com a melhor qualidade dos pescados, demonstrando que o motivo mais relevante na hora da compra seria a "Higiene" $(23,00 \%)$. Os homens, por outro lado, afirmaram optar pelo "Menor preço" (12,00\%)" (ALHO, 2019, p. 29). Essa constatação presente no trabalho de Alho (2019) pode ser relacionada aos dados desta pesquisa, uma vez que o atributo "qualidade" foi considerado o mais relevante no momento da compra por uma amostra que é formada em $70 \%$ por mulheres.

Contudo, existem outros fatores que precisam ser levados em consideração na hora da compra de produtos para consumo humano. Em se tratando do Mercado do Distrito de Icoaraci, estudos anteriores como o de Rosa et al. $(2019$, p. 6) revelaram "[...] que os consumidores deste local estão expostos ao risco de contaminação a partir da ingestão de alimentos adquiridos em seu interior, tendo em vista que os pescados são manipulados e armazenados sob péssimas condições”. A Portaria n 326, de 30 de julho de 1997 - que aprovou o Regulamento Técnico "Condições Higiênicos-Sanitárias e de Boas Práticas de Fabricação para Estabelecimentos Produtores/Industrializadores de Alimentos" -, no âmbito da Secretaria de Vigilância Sanitária do Ministério da Saúde, dispõe sobre uma série de requisitos gerais e essenciais de higiene e de boas práticas de fabricação para alimentos produzidos/fabricados para o consumo humano, objetivando à proteção da saúde da população (BRASIL, 1997).

A má conservação dos pescados comercializados em feiras e mercados públicos coloca em risco a saúde do consumidor, visto que o peixe é um alimento altamente perecível, tornandose um organismo profícuo na transmissão de microrganismos (SILVA JÚNIOR, 2014). Nesse sentido, no que se refere à qualidade do pescado consumido, indagou-se o seguinte: qual o atributo do pescado é considerado na hora da compra? Como resultado, obteve-se que 41,66\% $(\mathrm{n}=50)$ dos entrevistados apontaram que na hora da compra levavam em consideração a textura do pescado, 28,33\% $(\mathrm{n}=34)$ se atentavam para o aroma, $22,5 \%(\mathrm{n}=27)$ a cor e $7,5 \%(\mathrm{n}=9)$ a presença de hematomas, como mostra a Tabela 6. 
Tabela 6. Atributo considerado na hora da compra do pescado consumido entre os 120 consumidores do Mercado Municipal do Distrito de Icoaraci participantes da pesquisa que subsidiou este trabalho

\begin{tabular}{lrrr}
\hline Atributo do pescado é considerado na hora da compra & n & \% \\
\hline Cor & 27 & $22,5 \%$ \\
Presença de hematomas & 9 & $7,5 \%$ \\
Aroma & 34 & $28,33 \%$ \\
Textura & 50 & $41,66 \%$ \\
\hline Total & $\mathbf{1 2 0}$ & $\mathbf{1 0 0 \%}$ \\
\hline
\end{tabular}

Fonte: Própria (2019).

Em seguida, perguntou-se quais eram os critérios de frescor adotados antes e/ou na hora da compra desses pescados, os resultados mostram que: 48,33\% $(\mathrm{n}=58)$ dos entrevistados responderam a aparência dos olhos do peixe como fator de frescor, $34 \%(\mathrm{n}=28,33)$ se atentavam para a cor das guelras, 14,17\% $(\mathrm{n}=17)$ assinalaram a firmeza da carne, $9,17(\mathrm{n}=$ 11) a aderência das escamas, e $0 \%$ a presença do muco, conforme a Tabela 7 . Acerca destes dados, é primacial considerar as disposições da Agência Nacional de Vigilância Sanitária (BRASIL, 2016), uma vez que os peixes comprados frescos devem: ser livres de contaminantes físicos, químicos e biológicos; aparentar estar livres de manchas, furos ou cortes em sua superfície; as escamas devem estar firmes, consistentes e brilhosas; pele úmida; os olhos transparentes, brilhantes e salientes; a membrana que reveste a guelra precisa apresentar rigidez quanto à sua abertura; a face interna deve apresentar brilho característico, com os vasos sanguíneos cheios; as brânquias se apresentarem de cor avermelhada, úmidas e brilhantes, e com ausência de muco; odor característico e estar em bom estado de conservação sob uma grande camada de gelo. Com isso, deve-se atentar para essas características no momento da compra de um produto, pois elas são essenciais para evitar complicações à saúde. 
Tabela 7. Critério de frescor considerado antes da compra do pescado consumido entre os 120 consumidores do Mercado Municipal do Distrito de Icoaraci participantes da pesquisa que subsidiou este trabalho

\begin{tabular}{lrr}
\hline $\begin{array}{l}\text { Critério de frescor considerado antes da compra do } \\
\text { pescado }\end{array}$ & n & \% \\
\hline Aderência das escamas & 11 & $9,17 \%$ \\
Presença de muco & 0 & $0 \%$ \\
Cor das guelras & 34 & $28,33 \%$ \\
Aparência dos olhos & 58 & $48,33 \%$ \\
Firmeza da carne & 17 & $14,17 \%$ \\
\hline Total & $\mathbf{1 2 0}$ & $\mathbf{1 0 0 \%}$ \\
\hline
\end{tabular}

Fonte: Própria (2019).

Quanto à motivação do consumo de peixe, os dados mostraram que 50,83\% (n=61) dos consumidores entrevistados consumiam o peixe por conta de ser um alimento mais saudável, $39,16 \%(\mathrm{n}=47)$ pela facilidade de preparo, 35,83\% $(\mathrm{n}=43)$ por gostarem do sabor/textura, $8,33 \%(\mathrm{n}=10)$ pelo valor calórico, $5,83 \%(\mathrm{n}=7)$ pela marca do produto, $0,83 \%(\mathrm{n}=1)$ pela disponibilidade no mercado e $12,5 \%(n=15)$ por outras motivações, consoante a Tabela 8 . Para além da questão cultural de consumo na região, compreende-se a partir dos resultados que a população, ainda que informalmente, reconhece a importância nutricional desse alimento. Segundo Lopes et al. (2020), o pescado é caracterizado por elevada digestibilidade, pelo alto valor biológico, bem como pelo elevado teor de ácidos graxos poli-insaturados, sendo um alimento mais saudável do ponto de vista nutritivo. A partir de pesquisas amplamente divulgadas, importa assinalar que o consumo de pescado é fundamental para o desenvolvimento do sistema nervoso das crianças, visto que contribui com o processo de aprendizagem e as atividades física e mental (RAMALHO, 2019). 
Tabela 8. Motivação do consumo de peixe entre os 120 consumidores do Mercado Municipal do Distrito de Icoaraci participantes da pesquisa que subsidiou este trabalho

\begin{tabular}{lccc}
\hline Motivação do consumo de peixe & Sim & Não & Total \\
\hline Benefícios à saúde & $50,83 \%$ & $49,17 \%$ & $100,0 \%$ \\
Facilidade de preparo & $39,16 \%$ & $60,84 \%$ & $100,0 \%$ \\
Sabor / Textura & $35,83 \%$ & $64,17 \%$ & $100,0 \%$ \\
Valor calórico & $8,33 \%$ & $91,67 \%$ & $100,0 \%$ \\
Marca do produto & $5,83 \%$ & $94,17 \%$ & $100,0 \%$ \\
Disponibilidade & $0,83 \%$ & $99,17 \%$ & $100,0 \%$ \\
Outros & $12,5 \%$ & $87,5 \%$ & $100,0 \%$ \\
\hline
\end{tabular}

Fonte: Própria (2019).

Cascudo (1983) lista alguns ingredientes e preparos do bioma local que são a base da culinária paraense, entre eles se destacam: peixes de água doce (Aracu, Acari, Jaraqui, Mapará, Pirarucu, Tucunaré, Tambaqui); peixes de água salgada (Cação, Camurim, Corvina, Gurijuba, Piramutaba). De acordo com Lobato, Aires e Ravena-Cañete (2018, p. 264), essas características tornaram a gastronomia de Belém como “[...] uma das mais originais do Brasil, com ingredientes vindos de quase todos os cantos do mundo. Mas, certamente foi o uso dos recursos naturais locais que desenhou o destaque para a culinária paraense".

Sabendo-se que os consumidores residem no Distrito de Icoaraci, localizado às margens da Baía do Guajará, Estado do Pará, indagou-se qual a frequência em que consomem peixe e a preferência do modo de cocção (preparo). Como mostram os resultados (Tabela 9), 65\% (n = 78) dos participantes apontaram que consomem pescados pelo menos uma vez por semana. Quanto à forma, 43,33\% $(\mathrm{n}=52)$ preferem consumir o peixe assado, prosseguindo, 35,83\% (n $=43)$ assinalaram que preferem o peixe frito e 20,83\% $(n=25)$ peixe cozido (Tabela 10). Tal preferência por assado e frito deve certamente estar associada à tradição cultural indígena (ALHO, 2019). 
Tabela 9. Frequência do consumo de peixe entre os 120 consumidores do Mercado Municipal do Distrito de Icoaraci participantes da pesquisa que subsidiou este trabalho

\begin{tabular}{lrr}
\hline Frequência do consumo de peixe & $\mathbf{n}$ & $\mathbf{\%}$ \\
\hline Uma vez por semana & 78 & $65 \%$ \\
Duas vezes por semana & 25 & $20,83 \%$ \\
Três vezes por semana & 12 & $10 \%$ \\
Quatro vezes por semana & 4 & $3,33 \%$ \\
Todos os dias & 1 & $0,83 \%$
\end{tabular}

Total

120

$100 \%$

Fonte: Própria (2019).

Tabela 10. Preferência do modo de cocção do peixe consumido entre os 120 consumidores do Mercado Municipal do Distrito de Icoaraci participantes da pesquisa que subsidiou este trabalho

\begin{tabular}{|c|c|c|}
\hline Modo de preparo preferido & $\mathbf{n}$ & $\%$ \\
\hline Cozida & 25 & $20,83 \%$ \\
\hline Frito & 43 & $35,83 \%$ \\
\hline Assada & 52 & $43,33 \%$ \\
\hline In natura & 0 & $0 \%$ \\
\hline Total & 120 & $100 \%$ \\
\hline
\end{tabular}

Fonte: Própria (2019).

No que tange aos locais de consumo dos pescados pelos consumidores e por suas famílias, os dados (Tabela 11) revelaram que 79,16\% ( $\mathrm{n}=95)$ dos entrevistados consomem em suas residências, $13,33 \%(\mathrm{n}=16)$ em praias e apenas 4,16\% $(\mathrm{n}=5)$ em restaurantes. Sobre estes dados, salienta-se que culturalmente o paraense pouco frequenta restaurantes, preferindo o consumo do alimento caseiro. Afinal, ingerir alimentos na residência implica saborear um prato produzido por mães e avós, as quais têm certos cuidados nos preparos atrelados a uma carga emocional e cultural, que são importantes para promoção da saúde. Em estudo semelhante realizado por Santos et al. (2017), que buscou analisar o perfil do consumo de peixes com a população de Maceió, constatou-se que $92 \%$ dos entrevistados têm o hábito de consumir em casa, uma vez que os custos são menores que consumir em outros locais. 
Tabela 11. Local de maior consumo de pescado entre os 120 consumidores do Mercado Municipal do Distrito de Icoaraci participantes da pesquisa que subsidiou este trabalho

\begin{tabular}{lcc}
\hline Local de maior consumo do pescado & n & \% \\
\hline Residência & 95 & $79,16 \%$ \\
Restaurante & 5 & $4,16 \%$ \\
Praia & 16 & $13,33 \%$ \\
Outros & 4 & $3,33 \%$ \\
\hline Total & $\mathbf{1 2 0}$ & $\mathbf{1 0 0 \%}$ \\
\hline
\end{tabular}

Fonte: Própria (2019).

\section{Conclusões}

Conclui-se que no Distrito de Icoaraci, em Belém (PA), o perfil do consumidor é o seguinte: o pescado mais consumido é o peixe, sendo as peixarias e os supermercados os principais locais de aquisição e as residências os de consumo. Normalmente, os peixes são comprados congelados, uma vez na semana e a maior motivação para compra e consumo é o benefício à saúde. No entanto, compreendeu-se que, embora os consumidores constituintes da amostra e suas famílias se preocupem com os aspectos da qualidade higiênico-sanitária elementares nos momentos de compra, preparo e consumo de peixes, evidenciou-se que a vulnerabilidade social somada às formas de oferta e ao custo baixo inviabilizam, por vezes, tais cuidados e precauções. Afinal, com um número de pessoas por família representativo, buscar por pescados com preços mais acessíveis implica adquirir maiores quantidades desse alimento.

\section{Referências}

ALHO, T. V. L. Perfil do consumidor e fatores relevantes na compra de peixe no mercado de ferro do Ver-o-Peso, Belém (PA). 2019. 40 f. Trabalho de Conclusão de Curso (Graduação em Engenharia de Pesca) - Universidade Federal Rural da Amazônia, Belém, 2019.

BARROS, F. A. L. et al. Body morphometric measurements, yield and centesimal composition of king weakfishfillet. Biota Amazônia, Macapá, v. 9, n. 4, p. 16-19, 2019.

BRASIL. Ministério da Pesca e Aqüicultura. Pescado na alimentação escolar. Brasília: MPA, 2012.

BRASIL. Ministério da Saúde. Agência Nacional de Vigilância Sanitária (ANVISA). Escolha bem o seu pescado. Dicas para você levar um pescado fresquinho para casa. (Cartilha). Brasília: ANVISA, 2016.

BRASIL. Portaria n. 326 de 30 de julho de 1997. Dispõe sobre o Regulamento Técnico Sobre as Condições Higiênico-sanitárias e de Boas Práticas de Fabricação para Estabelecimentos Produtores/Industrializadores de Alimentos. Diário Oficial da União - DOU da República 
Federativa do Brasil. Ministério da Saúde. Brasília, DF: 30 jul. 1997. Disponível em: https://bvsms.saude.gov.br/bvs/saudelegis/svs1/1997/prt0326_30_07_1997.html. Acesso em: 16 jan. 2020.

CASCUDO, L. C. História da Alimentação no Brasil. 2. ed. São Paulo: Editora da USP, 1983.

CALDER, P. C. Omega-3 Fatty Acids and Inflammatory Processes: From Molecules to Man. Biochemical Society Transactions, United Kingdom, v. 45, n. 5, p. 1105-1115, 2017.

DURAN, N. D. et al. Availability and consumption of fish as convenience food - correlation between market value and nutritional parameters. Food Science and Technology, Campinas, v. 37, n. 1, p. 65-69, 2016.

FAO. Food and Agriculture Organization of the United Nation. The state of world fisheries and aquaculture. Roma: FAO, 2016.

FERREIRA, V. C. Estudo da comercialização e condições de armazenamento do pescado em duas feiras da cidade de Parintins/AM. 2019. $43 \mathrm{f}$. Trabalho de Conclusão de Curso (Graduação em Ciências Biológicas) - Centro de Estudos Superiores de Parintins, Universidade do Estado do Amazonas, Parintins, 2019.

LEANDRO, S. V. et al. Perfil de consumo e do consumidor de peixe no município de Sinop, Mato Grosso. Revista Agroecossistemas, Belém, v. 10, n. 1, p. 73-98, 2018.

LOBATO, F. H. S.; RAVENA-CAÑETE, V. "O açaí nosso de cada dia”: formas de consumo de frequentadores de uma feira amazônica (Pará, Brasil). Ciências Sociais UNISINOS, São Leopoldo, v. 55, n. 3, p. 397-410, 2019.

LOBATO, F. H. S.; AIRES, J. C. A.; RAVENA-CANETE, V. Belém, cidade criativa da gastronomia: uma Amazônia de sabores e de experiências turísticas. In: LAVANDOSKI, J.; BRAMBILA, A.; VANZELLA, E. (Org.). Alimentação e Turismo: criatividade, experiência e patrimônio cultural. 1ed.João Pessoa: Editora do CCTA, 2018, v. 2, p. 255-284.

LOPES, I. G.; OLIVEIRA, R. G. D.; RAMOS, F. M. Perfil do consumo de peixes pela população brasileira. Biota Amazônia, Macapá, v. 6, n. 2, p. 62-65, 2016.

LOPES, L. R. et al. Dimensões associadas ao consumo de pescado na Região Metropolitana de Belém - PA. Revista Contribuciones a las Ciencias Sociales, Texcoco, p. 1-19, junho, 2020.

LUZ, L. J. B. et al. Desenvolvimento de preparações para a alimentação escolar. Segurança Alimentar e Nutricional, Campinas, v. 27, p. 1-11. e020011, 2020.

MACIEL, E. S. et al. Avaliação do consumo de pescado durante campanha de incentivo em comunidade universitária. Revista de Ciência em Extensão, São Paulo, v.15, n. 1, p. 93-100, 2019.

MARTINS, F. J. Gastronomia do Pará: o sabor do Brasil. Belém: Abresi, 2014.

MATEUS, M. P. et al. Alimentação mediterrânica no linfedema. 1. ed. Faro: Universidade do Algarve, 2019. 
MEDEIROS, F. Anuário PeixeBR da piscicultura 2019. São Paulo: Associação Brasileira da Psicultura, 2019.

PINHEIRO, B. C. M. et al. Análise centesimal e de descrição do teor de aminoácidos presente nos sarnambis (protothaca antiqua) coletados na ilha de Algodoal-PA. Brazilian Journal of Development, Curitiba, v. 6, n. 4, p. 21677-21686, 2020.

PRODANOV, C. C.; FREITAS, E. C. Metodologia do trabalho científico: métodos e técnicas da pesquisa e do trabalho acadêmico. 2. ed. Novo Hamburgo: Universidade FEEVALE, 2013.

RAMAlHO, R. M. M. Controlo oficial de contaminantes no pescado. 2019. f. 99. Dissertação (Mestrado em Tecnologia e Segurança Alimentar) - Universidade Nova de Lisboa, Lisboa, 2019.

ROSA, M. Y. O. et al. O risco sanitário na comercialização de alimentos em um mercado público da Amazônia: um estudo de caso em Belém (PA). Scientia Plena, Aracaju, v. 15, n. 10, p. 1-7, 2019.

RUXTON, C. H. S. The benefits of fish consumption. Nutritivos on Bulletin, Somerville v. 36, n. 1, p. 6-19, 2011.

SANTOS, E. L. et al. Perfil do consumo de peixes na cidade de Maceió, Alagoas. Revista Científica de Produção Animal, Paraíba, v. 18, n. 1, p. 45-54, 2017.

SANTOS, E. J. R. et al. Qualidade higiênico-sanitária de tambaqui (Colossoma macropomum) comercializado na cidade de São Luís - MA. Ciência Animal Brasileira, Goiânia, v. 20, p. 1$12,2019$.

SILVA JÚNIOR, E. A. Manual de controle higiênico-sanitário em serviços de alimentação. 6. ed. atual. São Paulo: Varela, 2014.

SILVA, R. R. M. D. et al. Pescado na alimentação escolar: caracterização nutricional. Segurança Alimentar e Nutrição, Campinas, v. 24, n. 2, p. 169-179, 2017.

SOUSA, A. B. B. D.; ALMEIDA, N. M. D. Ácidos graxos em pescado: composição, influência da dieta e benefícios à saúde humana. CIENTEC-Revista de Ciência, Tecnologia e Humanidades do IFPE, Recife, v. 10, n. 1, p. 105-120, 2018.

SUÁREZ, H. et al. Importância de ácidos graxos poliinsaturados presentes em peixes de cultivo e de ambiente natural para a nutrição humana. Boletim do Instituto de Pesca, São Paulo, v. 28, n. 1, p. 101-110, 2018. 